\title{
O IMAGINÁRIO TRÁGICO DE RICARDO REIS: UMA EDUCAÇÃO PARA A INDIFERENÇA
}

Rogério de Almeida*

\section{RESUMO}

$\mathrm{O}$ artigo discute o imaginário trágico presente na obra de Ricardo Reis a partir de três dimensões: sua inserção na filosofia estóica e epicurista, seu paganismo e a educação para a indiferença. Ancora-se no Imaginário de Gilbert Durand, no trágico de Clément Rosset e utiliza a fenomenologia compreensiva como metodologia. O objetivo é compreender como a recorrência de imagens ligadas à brevidade da vida, à morte e ao destino configuram seu imaginário trágico.

Palavras-chaves: Fernando Pessoa. Ricardo Reis. Imaginário. Trágico. Educação.

\begin{abstract}
The article discusses the tragic imaginary present in Ricardo Reis' work starting from three dimensions: its insertion in the stoic and epicurean philosophy, its paganism and the education for the indifference. It is anchored in the Imaginary of Gilbert Durand, in the tragic of Clément Rosset and it uses the phenomenology as methodology. The objective is to understand how the recurrence of images connected with the brevity of the life, the death and the destiny they configure its imaginary tragic.
\end{abstract}

Keywords: Fernando Pessoa. Ricardo Reis. Imaginar., Tragic. Education.

\footnotetext{
* Doutor em Educação pela Universidade de São Paulo (USP). Professor da Faculdade de Educação da Universidade de São Paulo (FEUSP). E-mail: rogerioa@usp. br
} 


\section{Introdução}

Se há uma atitude frente à vida e ao destino que pode resumir o heterônimo mais altivo de Fernando Pessoa é a tranquilidade. Como viver, ou passar pela vida, está no cerne de sua obra poética. Aceitação tranquila do destino, aceitação da brevidade da vida, aceitação do tempo que passa e leva consigo a permanência: fomos, já não somos; somos, já não fomos.

Nada, senão o instante, me conhece.

Minha mesma lembrança é nada, e sinto

Que quem sou e quem fui

São sonhos diferentes (PESSOA, 1996, p. 133).

Atado ao instante, o presenteísmo faz com que Ricardo Reis não se prenda a lembranças do passado. O que passou é de outro que não eu. Resta-lhe o destino, o Fado, superior a ele e aos próprios deuses, com quem conversa, pedindo que dele não se lembrem.

Quero dos deuses só que me não lembrem.

Serei livre - sem dita nem desdita,

Como o vento que é a vida

Do ar que não é nada.

O ódio e o amor iguais nos buscam; ambos,

Cada um com seu modo, nos oprimem.

A quem deuses concedem

Nada, tem liberdade (PESSOA, 1996, p. 147).

Passando ao largo do amor e do ódio, em uma palavra, dos extremos, Ricardo Reis busca a calma de passar pela vida sem se entregar aos sentimentos. Essa é a sua liberdade, embora saiba que "só na ilusão da liberdade / A liberdade existe" (PESSOA, 1996, p. 107). Poderíamos glosar os versos e completá-los sem prejuízo ao poeta: só na ilusão da tranquilidade, a tranquilidade existe. Porque por detrás da tranquilidade buscada, esconde-se uma inquietude por ser, por conhecer, por realizar-se. 
Reis, ao aderir a uma espécie de estoicismo epicurista, está buscando uma compreensão trágica da vida, sobre a qual erige o seu imaginário poético, simbolizado pelas flores, pelo rio, pelo destino, pelos deuses, enfim, por tudo o que remete à brevidade da vida.

Breve o dia, breve o ano, breve tudo.

Não tarda nada sermos (PESSOA, 1996, p. 136).

Na primeira pessoa do plural ou na segunda do singular, Reis vai compondo uma espécie de código de como viver.

Colhe as flores mas larga-as,

Das mãos mal as olhaste.

Senta-te ao sol. Abdica

E sê rei de ti próprio (PESSOA, 1996, p. 104).

Abdicar à vida para reinar sobre si, sobre suas emoções, sobre seus pensamentos é o que nos ensina Reis. Sua educação é a da indiferença. Colher flores, mas largá-las. Não seria essa a indiferença da morte, quando nos colhe? As flores murcham, o dia anoitece, a vida morre, mas, enquanto houver flores, dias e vida, seremos reis, desde que renunciemos a sê-lo. Pensamento paradoxal que expressa, bem mais que um jogo de palavras, a vida integrada ao seu contrário, a morte. Morte que é o fim da vida, mas morte que é vivida diariamente, nas pequenas mortes de todos os dias, seja a das flores, seja a do que imaginamos ser.

Por meio desse imaginário ${ }^{1}$ trágico presente na obra de Ricardo Reis, pretende-se mostrar como sua visão de mundo se constitui e nos direciona para a reflexão sobre a morte e a vida, da qual se sobressai uma educação para a indiferença.

\footnotetext{
${ }^{1} \mathrm{O}$ imaginário define-se como "o conjunto das imagens e relações de imagens que constitui o capital pensado do homo sapiens - aparece-nos como o grande denominador fundamental onde se vêm encontrar todas as criações do pensamento humano" (DURAND, 1997, p. 18).
} 


\section{Estoicismo e Epicurismo}

As filosofias epicurista e estóica desenvolvem-se no período de decadência grega, por volta do ano 300 a.C., e recebe a influência de cultos e fés orientais. "As crenças místicas e supersticiosas que haviam adquirido raízes entre os povos mais pobres de Hélade foram reforçadas e divulgadas; e o espírito oriental de apatia e resignação encontrou um solo pronto na Grécia decadente e abatida" (DURANT, 1996, p. 110).

A vida pública, de fato, para tais filosofias, perde sua relevância e cede lugar a questões de como viver na esfera privada. Uma sociedade desestabilizada, em declínio, cujos valores instituídos se apartam da realidade cotidiana, não pode senão favorecer a indiferença, ou a apatheia. Tornando-se insensível à dor e ao sofrimento, no recolhimento da vida privada, entre as alamedas do jardim, é possível extrair a tranquilidade, ou prazer, com que viver a brevidade dos nossos dias.

É assim que, para Reis, essa atitude de indiferença, de ataraxia - a imperturbabilidade da alma por meio do equilíbrio e da moderação na escolha dos prazeres - circunscreve-se à situação; está, portanto, em relação dialógica com as emanações da esfera pública: "É enquanto os bárbaros (os cristãos) dominam que a atitude dos pagãos deve ser esta" (PESSOA, 1998, p. 140).

Pessoa, na criação de Reis, ao dotá-lo de um paganismo helênico, traçou um paralelo entre a época da decadência grega e a própria decadência moderna.

Tanto o estoicismo como o epicurismo - a apática aceitação da derrota e o esforço para esquecer a derrota nos braços do prazer - eram teorias sobre como o indivíduo ainda poderia ser feliz, embora subjugado ou escravizado (DURANT, 1996, p. 110).

Para os estóicos, cuja figura central foi um mercador fenício de nome Zenão, deve-se observar a virtude, afastando-se das paixões, de modo a buscar um posicionamento sobre si mesmo, uma concordância consigo mesmo, vivendo de acordo com a natureza. "Há um poderoso princípio da natureza que tem muitos nomes: chama-se fogo e sopro da vida, mas 
também espírito, razão e destino. Enfim é designado como a divindade e identificado com o Deus supremo" (WEISCHEDEL, 2000, p. 76). Assim, os deuses estão presentes, interferem, no real e, consequentemente, no próprio homem, que participa da natureza trazendo-a em sua interioridade. A compreensão de si realiza-se, portanto, por meio da razão, que deve se integrar à razão cósmica, às leis da natureza.

Se o homem age realmente a partir de si mesmo, então age desde o si que, naturalmente, é racional e divino, realizando desse modo sua liberdade justamente nos quadros da necessidade universalmente abrangente. A liberdade consiste, pois, na inserção voluntária na ordem divina (WEISCHEDEL, 2000, p. 77).

As paixões devem ser evitadas, pois turvam a razão, e é a razão que permite ao homem estar de acordo com seu princípio interior, princípio que é divino, natural. Esta é a essência da virtude: cumprir o dever, "obedecer à voz divina no interior" (WEISCHEDEL, 2000, p. 78), ou ainda, cumprir o destino, aceitá-lo também.

Reis é estóico na medida em que aceita e cumpre o destino, mas não crê que esse destino afine-se com a voz divina; antes, crê que o Fado rege os próprios deuses. Não nega a força dos deuses ou sua realidade no mundo, mas também não busca sua intervenção, apenas sua indiferença: "Quero dos deuses só que não me lembrem" ou "Aos deuses peço só que me concedam / O nada lhes pedir" (PESSOA, 1996, p. 147).

Essa adesão de Reis à situação não coaduna com a ética do dever estóica. Não há que se buscar, também, a razão com que se atingir a virtude, basta ser o que somos (PESSOA, 1996, p. 147):

Não tenhamos melhor conhecimento

Do que nos coube que de que nos coube.

Cumpramos o que somos.

Nada mais nos é dado.

Mas Reis é estóico ao evitar as paixões que pudessem perturbar sua tranquilidade, presente ou futura. Assim, pede à Lídia, musa que toma de empréstimo a Horácio, que (PESSOA, 1996, p. 101): 
Amemo-nos tranquilamente, pensando que podíamos, Se quiséssemos, trocar beijos e abraços e carícias, Mas que mais vale estarmos sentados ao pé um do outro Ouvindo correr o rio e vendo-o.

Reis é e não é estóico. É e não é, também, epicurista.

$\mathrm{O}$ epicurismo coloca o sumo bem no prazer. $\mathrm{Na}$ sua forma mais rigorosa, restringe-se a buscar o prazer negativo que consiste na ausência da dor. O ideal do sábio é a ataraxía, a paz imperturbável do espírito. Quanto aos prazeres positivos limitam-nos aos absolutamente necessários (TRINGALI, 1995, p. 68).

É famoso o jardim de Epicuro, domus onde ensinava seus discípulos, onde gozava os prazeres do intelecto, da conversa e da convivência. Seus detratores tentam associá-lo a um prazer descontrolado, excessivamente sensual, restrito ao âmbito da carne. Mas esses prazeres não combinam com a ética do jardim, cujo prazer, que de fato é a origem e o fim da vida feliz, é atingido por um sereno equilíbrio da alma, dirigido aos sutis encantos do espírito: "a conversação, a audição de música, a contemplação de obras de arte e, particularmente, a filosofia" (WEISCHEDEL, 2000, p. 70).

Para os epicuristas, a natureza é formada de átomos, invisíveis partículas elementares, que se combinam, se separam, vibram em eterno movimento, em eterno retorno. É a velha concepção de Demócrito. "Concebido dessa forma, o mundo deixa de ser a perigosa morada do homem. O filósofo pode então deixar o mundo entregue a si mesmo, não precisando continuar, na quietude do espírito, a se preocupar com ele" (WEISCHEDEL, 2000, p. 72). Tal visão de mundo dispensa também a intervenção dos deuses. Eles existem, são mais perfeitos, mais bem-aventurados, mas vivem em uma esfera independente do mundo dos homens.

Assim, a morte, que dissolve o elo dos átomos que constituem corpo e alma, deve ser encarada com tranquilidade. Não há imortalidade, nem julgamento, nem destino futuro com o qual se preocupar. "Nada pode então impedir o homem de gozar a sua limitada existência em todas suas alegrias deste mundo" (WEISCHEDEL, 2000, p. 73). 
Reis é epicurista ao adotar um modo de ser diante do mundo que não reconhece a intervenção dos deuses, que não concebe a natureza como um princípio divino e por buscar a mesma tranquilidade, diante da vida e da morte, e a mesma indiferença à vida pública que os epicuristas adotavam. Também, para Reis, não devemos nos preocupar com a intervenção dos deuses, recolhendo-nos à esfera privada, aceitando a passagem do tempo e a inevitabilidade da morte com tranquilidade. No entanto, como o próprio Pessoa adverte (PESSOA, 1998, p. 140):

Resume-se num epicurismo triste toda a filosofia da obra de Ricardo Reis. (...) Buscando o mínimo de dor, o homem deve procurar sobretudo a calma, a tranquilidade, abstendo-se do esforço e da atividade útil. (...) Devemos buscar dar-nos a ilusão da calma, da liberdade e da felicidade, cousas inatingíveis porque, quanto à liberdade, os próprios deuses sobre que pesa o Fado - a não têm; quanto à felicidade, não a pode ter quem está exilado da sua fé e do meio onde a sua alma devia viver; e quanto à calma, quem vive na angústia complexa de hoje, quem vive sempre à espera da morte, dificilmente pode fingir-se calmo.

Reis, diferentemente dos epicuristas, não considera o prazer como o bem supremo. Na verdade, é indiferente quanto ao prazer. "Quer gozemos, quer não gozemos, passamos como o rio” (PESSOA, 1996, p. 101). Não há muito o que buscar, basta aceitar o mínimo, o comedimento, a passagem do tempo.

Reis é um aristocrata; nem estóico nem epicurista, tem um pouco dos dois, principalmente no que concerne a adiar qualquer atitude em relação ao mundo para optar pelo recolhimento indiferente da vida privada, cultivada sem grandes emoções ou sofrimentos, buscando uma calma qualquer.

Calma que o proteja da "angústia complexa" da modernidade, que pune a liberdade do homem, coibindo qualquer tentativa de exercê-la. "A declarada independência absoluta do homem, que na teoria estóica era considerada como a virtude fundamental do homem, na teoria cristã tornase o seu vício e erro fundamentais" (CASSIRER, 2001,p. 21). É punindo a liberdade que a religião cristã submete o homem a uma conduta dual, pois 
concebe duas realidades: a espiritual, que guardaria o verdadeiro sentido do ser e a eternidade do tempo, e a material, fonte do erro, do mal e da finitude e que, portanto, deve ser negada. A filosofia moderna, de certa forma, opera com a mesma dualidade: a metafísica, que guardaria o verdadeiro sentido do ser e do devir, e o real, materialidade pobre e superficial (contra a qual o racionalismo erige seu pensamento denegatório).

As duas máximas fundamentais do epicurismo podem aparecer, com justa razão, como pensamentos particularmente curtos e pobres. Assimilar a verdade à existência material, o bem à experiência do prazer, equivale certamente a frustrar toda expectativa de elucidação em profundidade e a limitar-se, quanto a esses dois pontos, ao mais minimalista dos discursos. Mas, por outro lado, deve-se observar que a tentativa de assimilar a verdade a outra coisa que não a matéria, o bem a outra coisa que não o prazer, leva geralmente a enunciados eles mesmos muito mais suspeitos e absurdos que as fórmulas epicuristas (ROSSET, 2002, p. 34).

De certa forma, nesta concepção filosófica, a profundidade emerge à superfície e o sentido do dado material torna-se imanente, ou seja, é expresso por esse próprio dado, é esse próprio dado:

A natureza é só uma superfície.

$\mathrm{Na}$ sua superfície ela é profunda

E tudo contém muito

Se os olhos bem olharem.

Aprende, pois, tu, das cristãs angústias,

Ó traidor à multíplice presença

Dos deuses, o não teres

Véus nos olhos nem na alma (PESSOA, 1996, p. 146).

Desvelar os olhos é olhar para a própria superfície da Natureza, fazer com que o sentido não seja procurado na sua profundidade, pois a profundidade está na superfície e na multiplicidade das coisas singulares que a compõe. É nesse sentido que a verdade é a matéria e o prazer o bem. Mas poderíamos dar um passo além e abrir mão da verdade e do bem, até 
mesmo do prazer, e então ficaríamos apenas com a matéria, como o fez Ricardo Reis: a matéria não implica verdade, mas destino.

Ricardo Reis é estóico e epicurista, mas vai além do estoicismo e do epicurismo ao romper com o dever do primeiro e com a felicidade do segundo. Nenhum princípio orienta seu mundo, a não ser a aceitação do Fado. Indiferente ao dever, indiferente ao prazer, Reis abraça uma consciência trágica, pois sabe que a tranquilidade e a felicidade, que em suas odes canta, não passam de fingimento. Mas, se entendermos fingimento como queria Pessoa, ou seja, como forjamento, criação estética de mitos, de modos de ser, de pensar e de sentir, então compreenderemos Reis: a valorização do polo da ataraxia, da apatia, da impassibilidade revela a integração do seu contrário, a inquietude de existir, a angústia diante da morte e do tempo que passa, a insatisfação com um mundo que lhe é hostil.

\section{O Paganismo de Ricardo Reis}

Para Ricardo Reis, há duas religiões pagãs, uma saturniana e outra olímpica. Os deuses saturnianos derivam de Urano (o Céu), cujo filho Saturno (Cronos) the destrona e, a partir de seu reinado, passa a devorar seus filhos. Quando Júpiter (Zeus) destrona seu pai, inicia-se o império olímpico, cujos deuses são visíveis e próximos, vivendo no plano da imanência, habitando a natureza e também subordinados ao Fado.

A religião saturniana é espiritualista, fazendo crer que o mundo é mais extenso, que há um além, que há uma Providência divina, que tudo rege, que depois da morte a alma há de prestar contas dos seus atos. (...) Ricardo Reis repudia a religião saturniana e se filia à religião olímpica. A natureza é uma mera superfície sem dentro. Os deuses têm corpos. Todavia, em seu tempo, dominam as religiões saturnianas, por isso ele é um inconformado (TRINGALI, 1995, p. 51).

Seu inconformismo enxerga o cristianismo, ou cristismo, como produto da decadência romana, e a teologia cristã como uma heresia que viola as leis do equilíbrio. O paganismo, para Reis, é a verdadeira base da nossa civilização e não deve, portanto, ser negado para a afirmação de um 
único Deus. Daí atribuir a Cristo, que considera mais um entre os deuses, um papel modesto, vendo-o como arquétipo ou mito, o deus que faltava, pois que não havia um deus triste e comovido pela dor humana, o deus que enxuga "o pranto dos humanos que sofrem" (PESSOA, 1996, p. 119).

É de interesse notar que Reis não se opõe a Cristo ("Não a ti, Cristo, odeio ou te não quero."), mas aos seus cultores que o querem maior que os outros deuses ou "vedar o eterno culto das presenças maiores ou parceiras" (PESSOA, 1996, p. 119). Os cristãos, ou crististas, negam o mundo terreno para afirmar um outro mundo, o reino dos céus, onde a eternidade se dá em oposição à finitude humana. Essa lógica antitética não consegue conceber a multiplicidade pagã (PESSOA, 1996, p. 118):

Cura tu, idólatra exclusivo de Cristo, que a vida

É múltipla e todos os dias são diferentes dos outros,

E só sendo múltiplos como eles

'Staremos com a verdade e sós.

A nossa solidão, no entender de Reis, é similar à dos deuses, pois estamos ligados a eles, independente mesmo de sua existência concreta. "A rigor, não existem deuses, existe somente a crença em deuses na memória dos homens" (TRINGALI, 1995, p. 51). Ou seja, estamos ligados aos deuses pela visão que deles temos. Na visão de Reis, os deuses habitam a mesma natureza que nós, o mesmo mundo - daí seu paganismo olímpico - e é suscetível ao Fado.

Reis pratica o paganismo como chave para ler a pluralidade da Natureza, evitando deslizar para a tentação de uma unidade pré-existencial:

A religião pagã é politeísta. Ora a natureza é plural. A natureza, naturalmente, não nos surge como um conjunto, mas como "muitas coisas", como pluralidade de cousas. Não podemos afirmar positivamente, sem o auxílio de um raciocínio interveniente, sem a intervenção da inteligência na experiência direta, que exista, deveras, um conjunto chamado Universo, que haja uma unidade, uma cousa que seja uma, designável por natureza. A realidade, para nós, surgenos diretamente plural (PESSOA, 1998, p. 175). 
Negar a natureza como princípio de unidade, bem como a possibilidade de qualquer outro princípio que se coloque no lugar - daí a afirmação politeísta de seu paganismo -, é configurar o trágico de seu imaginário, pois é a afirmação da indiferença, da ausência de princípio (seja natural ou divino), da inexorabilidade do tempo que define o trágico (ROSSET, 1989).

Em Reis, a passagem do tempo é morte, o que vem é o mesmo que já foi, pois está destinado a passar, restando-nos o presente e o que somos ("Quem sou e quem fui / São sonhos diferentes"). "A vida do homem sensato decorre assim, em equilíbrio instável à beira do abismo, como a de um jogador louco que a todo o momento arrisca toda a aposta" (BRÉCHON, 1999, p. 229). Mas Reis não é louco e o triunfo de sua razão de jogador é apostar tudo, sem dúvida, como quem se põem inteiro em tudo que faz, mas garantindo que esse tudo seja pouco, daí despojar-se de todo reinado, de todo envolvimento amoroso, de tudo o que seja da ordem do passional, pois é a emoção que, no jogo, faz com que o homem se envolva e tema perder. Reis já se sabe perdedor, pois o fim do jogo é morrer, mas continua passivamente jogando, pois é este o destino.

Como acima dos deuses o Destino

É calmo e inexorável,

Acima de nós-mesmos construamos

Um fado voluntário

Que quando nos oprima nós sejamos

Esse que nos oprime,

E quando entremos pela noite dentro

Por nosso pé entremos.

Só esta liberdade nos concedem

Os deuses: submetermo-nos

Ao seu domínio por vontade nossa.

Mais vale assim fazermos

Porque só na ilusão da liberdade

A liberdade existe (PESSOA, 1996, p. 107). 
Ser o opressor de si mesmo é aceitar o destino e a realidade do tempo que passa e conduz à morte. Submeter-se ao domínio dos deuses é aceitar sua expressão mítica. "Os deuses não morreram: o que morreu foi a nossa visão deles” (PESSOA, 1998, p. 179). E ver os deuses é aceitar que expressam arquétipos ${ }^{2}$ do que somos ou do que podemos ser, enfim, de nosso próprio destino:

Nós, imitando os deuses,

Tão pouco livres como eles no Olimpo,

Como quem pela areia

Ergue castelos para encher os olhos,

Ergamos nossa vida

E os deuses saberão agradecer-nos

O sermos tão como eles (PESSOA, 1996, p. 107).

Ser como os deuses é erguer sonhos que possam imitá-los, não por sua natureza divina, mas por serem eles mesmos seres que se iludem. Nesse sentido, podemos afirmar que o paganismo de Reis não é mais que outra maneira de expressar essa crença na expressão mítica, não pelo que exprime, pois o que exprime é inexprimível, mas por se constituir um modo, uma linguagem, uma possibilidade de falar do dado inefável que constitui a vida. Assim, a própria vida assume a estrutura mítica, constituindo-se como uma narrativa dinâmica, expressa pela mediação simbólica, característica fundamental da cultura humana, que é dotar de sentido a existência, através do imaginário, para poder dar conta do tempo que passa. Assim:

Gozo sonhado é gozo, ainda que em sonho.

Nós o que nos supomos nos fazemos,

Se com atenta mente

Resistirmos em crê-lo.

\footnotetext{
${ }^{2} \mathrm{O}$ arquétipo define-se pela invariância, falta de ambivalência e universalidade. "O arquétipo é, portanto, uma forma dinâmica, uma estrutura que organiza as imagens, mas sempre ultrapassa as concretudes individuais, biográficas, regionais e sociais da formação das imagens" (DURAND, 1988, p. 60).
} 
Não, pois, meu modo de pensar nas coisas,

Nos seres e no fado me consumo.

Para mim crio tanto

Quanto para mim crio.

Fora de mim, alheio ao que penso,

O Fado cumpre-se. Porém eu me cumpro

Segundo o âmbito breve

Do que de meu me é dado (PESSOA, 1996, p. 128).

Reis não busca o gozo da ilusão, no qual se pode crer, mas o da criação, a que pode cumprir, segundo seu modo de pensar (e poderíamos acrescentar sentir) as coisas. Fora isso o Fado cumpre-se. Mas aqui, no domínio da criação, Reis pode ser rei de si, pois abdicou ao que quer que seja exterior a esse domínio.

Mesmo afirmando crer na existência dos deuses, Reis não se constitui religioso, pois não pede nada a eles, deles nada cobra, nem mesmo os crê donos da própria liberdade, mas expressão arquetípica de nossa vontade de ser como eles. E aqui o único caráter sagrado possível a Reis: a mitopoiesis ${ }^{3}$. Se a própria vida não é sagrada, se os deuses não são sagrados, somente a criação poética (e mítica) da vida e dos deuses o é. É na poesia, como expressão do imaginário, que o homem pode fazer parte do exercício de criar. É assim que Reis se cumpre, é na criação que Reis se mostra inteiro, é por meio dela que ele pode expressar sua sensibilidade afeita à incidência conjunta dos opostos: seu desassossego "está presente em negativo no discurso da serenidade” (BRÉCHON, 1999, p. 231).

Portanto, Reis é adepto do paganismo mais pela pluralidade que o caracteriza do que pela crença convicta no mundo e na vida dos deuses, pois o poeta horaciano criado por Pessoa compreende-os bem demais para crer. "Só é possível crer no que não se compreende, e é completamente impossível

${ }^{3}$ Criação de mitos ou sua atualização por meio de novas roupagens para antigos mitos. É bom não nos esquecermos de que o próprio Pessoa desejava ser "um criador de mitos, que é o mistério mais alto que pode obrar alguém da humanidade" (PESSOA, 1998, p. 84). 
crer no que se compreende" (ROSSET, 2002, p. 76). E é como arquétipo das possibilidades humanas (GUSDORF, 1987) que Reis vê aos deuses:

A pluralidade dos deuses é, com efeito, um dos característicos do paganismo. Mas cumpre entender qual o sentido que subjaz essa pluralidade (...). E para isso é preciso ter presentes três cousas: que acima dos deuses, no sistema pagão, paira sempre o Ananke, o Fatum, incorpóreo, submetendo os deuses como os homens aos seus decretos inexplicados; que os deuses se destacam dos homens e lhe são superiores por uma questão de grau, que não de ordem, que eles são antes homens aperfeiçoados (...); que um arbítrio absoluto e não uma razão de ordem moral (...) rege as relações dos deuses com os homens (PESSOA, 1998, p. 181-182).

A primeira afirmação é a da pluralidade, a segunda a subordina a um princípio: Ananke ${ }^{4}$ ou Necessidade, poder ordenador que rege homens, deuses e a natureza, chamado também de Fatum, "personificação romana do destino" (MARTINEZ, 1997, p. 150), cuja raiz relaciona-se ao verbo "falar"; ou seja, o Destino se fala, mas não se explica; pode-se falar dele, mas não explicá-lo. Ao menos é assim que se apresenta na obra de Reis, que todo o tempo subordina a própria realidade a esse princípio: "Flores que colho, ou deixo, / Vosso destino é o mesmo" (PESSOA, 1996, p. 123).

$\mathrm{O}$ destino coincide com a própria existência. Nesse sentido, é esclarecedora a leitura que Deleuze (2003, p. 7) faz dos estóicos: "Remetem as causas às causas e afirmam uma ligação das causas entre si (destino). Remetem os efeitos aos efeitos e colocam certos laços dos efeitos entre si." É assim que, para Reis, é indiferente colher ou não as flores, pois trata-se apenas de efeitos, a causa de sua existência é a mesma: ser breve. Esse o seu destino. Esse o destino dos homens.

Disso decorre que os deuses também não são causas, mas efeitos, pois estão subordinados ao destino. Se são superiores, o são por grau,

\footnotetext{
4 "As etimologias mais usuais de ananke relacionam-se com o alemão eng (estreito), como angina, angst, e ansiedade, com agchein (grego), estrangular, e com agham (sânscrito), mal (...). A palavra latina para ananke é necessitas. Aqui também encontramos a noção de um "vínculo estreito" ou "laço íntimo" (HILLMAN, 1997, p. 15).
} 
ou seja, personificam arquétipos de sensibilidade que, em essência, não diferem das humanas, mas as potencializam, ou como quer Reis, as aperfeiçoam. Ciúme, ódio e amor nos movem tanto quanto aos deuses, assim como nossos desejos de heroísmo, de prazer ou de imortalidade (ou os deles): "[os pagãos têm] necessidade de objetivar tudo, para quem os deuses são, não fantasias concretizadas, mas probabilidades aumentadas" (PESSOA, 1998, p. 182).

A terceira coisa que subjaz à pluralidade pagã, segundo Reis, é o arbítrio das relações dos deuses com os homens. Não uma conduta moral norteando essas relações, mas uma liberdade ética ou uma ética livre que as permeia, pois as leis morais não têm realidade metafísica, uma vez que se circunscrevem à cidade, ao povo, a uma determinada cultura. Esse pensamento possibilita uma relação de liberdade dos homens com os deuses, ou dito de outra forma, do homem com suas possibilidades (ou probabilidades) aumentadas. Nesse sentido, o modo de ser de cada um, seu ethos, propiciará diferentes formas de contato com essas divindades, o que remete à própria pluralidade subjacente ao paganismo.

No caso de Reis, sua relação com os deuses é nada pedir a eles e deles nada esperar, pois aceita, de princípio, o Fado a que está, tanto quanto os deuses, submetido. Como uma flor, tanto faz que os deuses o acolham ou o deixem, o seu destino é o mesmo. O poeta não opõe a materialidade do mundo à espiritualidade de um outro plano, mas funde essas duas dimensões numa mesma realidade, cujo princípio é o destino inexorável de existir.

\section{Uma Educação para a Indiferença}

Reis é trágico, sabe-se num mundo sem unidade e passa por ele sem envolvimento, controlando suas emoções e extraindo beleza das pequenas coisas, atingindo assim um conhecimento da vida que é sua sabedoria. Sabedoria que o iguala aos deuses. Sabedoria que deles o afasta.

Para o trágico, não há como modificar a Natureza. Para fazermos uso de uma argumentação de Beatriz Fétizon (2002): podemos cortar árvores, pavimentar vales e montes, até mesmo mudar o azul do céu, mas como modificar o acaso que engendra o fato de haver cores, céu e árvores? 
“Quando o pensamento trágico assimila o ser a um 'dado', ele tem em vista uma noção de reunião fortuita na qual nenhum reajustamento pode modificar a natureza naquilo que ela tem de casual" (ROSSET, 1989, p. 50). Ou seja, o acaso não é modificável, de onde nada acontece. Ou tudo acontece, mas com a ressalva de que o que acontece - movimento - não modifica em nada a natureza do acaso. É um acréscimo que não modificará a qualidade do que é acrescido, ou seja, é um acréscimo que não modifica o destino, pois para o destino, ou contra o destino, não há acontecimento. Nem mesmo aos Deuses é permitido modificar o destino. Também eles a ele são submissos.

Como a natureza se expressa pela diversidade material de tudo o que existe e é regida pelo acaso, nada pode modificá-la, sua expressão é o destino, o Fado, a existência que nos é dada. E no ciclo de nascimento e morte, morte e nascimento, que perfaz a natureza, o homem, na sua brevidade, vê-se vítima da indiferença do destino.

A natureza nos ensina: saís deste mundo como nele entrastes. Passastes da morte à vida sem que fosse por efeito de vossa vontade e sem temores; tratai de vos conduzirdes de igual maneira ao passardes da vida à morte; vossa morte entra na própria organização do universo: é um fato que tem seu lugar assinalado no decurso dos séculos (MONTAIGNE, 1987, p. 49).

Diante da inexorabilidade da morte, a vida se constrói nas margens impostas pelo limite do tempo. Na curta duração que ao homem é dada, não há que se esquecer da morte, mas integrá-la à vida, saber que se vai morrer e que só a adesão ao presente pode dar algum sentido para a existência, ainda que um sentido imaginário, como o são todos. O desejo de Reis de encontrar na morte o resumo de uma vida tranquila, revela justamente a inquietude da vida, expressa pelo tempo que passa, gerador da angústia primordial (DURAND, 1997).

O que o tempo nos ensina é que cada dia que nos dá é um dia que tira. Mais um dia de vida, menos um para a morte. Se lembrarmos que nascer é entrar no tempo, precisaremos nos preparar para dele sair. Porque o tempo é indiferente. Porque na vida, a seguirmos a lição de Reis, também temos que ser. 
O tempo nos ensina o que não adianta aprender. Sabemos da morte, mas não sabemos morrer, que vale o seu justo contrário - sabemos da vida mas não sabemos viver - ou seu quiasmo: sabemos da morte mas não sabemos viver, sabemos da vida mas não sabemos morrer.

Poeticamente, assim o expressou Reis:

Não quero recordar nem conhecer-me.

Somos demais se olhamos em quem somos.

Ignorar que vivemos

Cumpre bastante a vida.

Tanto quanto vivemos, vive a hora

Em que vivemos, igualmente morta

Quando passa conosco,

Que passamos com ela.

Se sabê-lo não serve de sabê-lo

(Pois sem poder que vale conhecermos?),

Melhor vida é a vida

Que dura sem medir-se (PESSOA, 1996, p. 122).

Filosoficamente, encontramos a justa transposição dos versos para o pensamento trágico de Clément Rosset (2002, p. 22):

O que há de mais agudo e de mais notório no que se chama a condição humana parece-me residir precisamente nisto: ser munida de saber - diferentemente dos animais ou dos objetos inanimados - mas, ao mesmo tempo ser desprovida dos recursos psicológicos suficientes para fazer face a seu próprio saber, ser dotada de um acréscimo de conhecimento, ou ainda de um "olho a mais", como diria André Green, que faz indistintamente seu privilégio e sua ruína - em suma, saber mas não poder fazer nada.

De fato, temos consciência da morte, mas rejeitamos a ideia da morte, somos incapazes de admitir sua verdade, mas plenamente capazes de entendê-la. Portanto, saber sem sofrer é algo que não se situa 
entre as faculdades do homem, daí a necessidade de alguma assistência extraordinária, que os Epicuristas chamam de prazer, que Pascal chama de graça, Rosset de alegria e Reis de calma. Mas poderíamos dizer que prazer, graça, alegria ou calma são sentidos derivados do próprio dinamismo do Imaginário, que por meio do trajeto antropológico propicia o surgimento e o tratamento dessas imagens-conceito, respostas imaginárias à angústia primordial.

Diante da inexorabilidade da morte, em vez de imaginariamente esquecê-la, Reis opta por torná-la sempre presente e consciente, optando por imaginariamente esquecer a vida ("Ignorar que vivemos / Cumpre bastante a vida"). É esse movimento que caracteriza o imaginário trágico de Ricardo Reis.

O saber trágico traduz-se pela aceitação do destino e pela indiferença diante de qualquer sentido transcendente, qualquer engajamento, qualquer finalidade para a existência. Se a morte é dada indiferentemente a cada homem, é com a mesma indiferença que cada homem deve viver. Que diferença poderia nos livrar da morte?

Essa educação para a indiferença, lição última da poesia de Reis, é também educação para o acolhimento, razão pela qual, na sua crítica ao cristianismo, jamais tenha negado Cristo, mas o que dele fizeram. Reis o reconhece como o deus que faltava. Haveria melhor lição de adesão à pluralidade do que esta: acolher o deus cristão no corpo mesmo de uma religião panteísta?

A educação de Reis, então, partindo da inexorabilidade da morte, ensina a indiferença diante da vida, que se resolve no acolhimento da existência mesma, único reinado que resta. É assim que, por meio da abdicação de si, o poeta torna-se rei. Ou melhor, torna-se plural: Reis.

\section{Referências}

BRÉCHON, R. Estranho estrangeiro: uma biografia de Fernando Pessoa. Rio de Janeiro: Record, 1999.

DELEUZE, G. Lógica do Sentido. São Paulo: Perspectiva, 2003.

DURAND, G. A Imaginação Simbólica. São Paulo: Cultrix; EDUSP, 1988. 
. As Estruturas Antropológicas do Imaginário. São Paulo: Martins Fontes, 1997.

DURANT, W. A História da Filosofia. Coleção Os Pensadores. São Paulo: Nova Cultural, 1996.

FÉTIZON, B. Sombra e Luz: O Tempo Habitado. São Paulo: Zouk, 2002.

GUSDORF, G. Professores Para Quê? São Paulo: Martins Fontes, 1987.

HILlmaN, J. (Org.). Encarando os Deuses. São Paulo: Cultrix; Pensamento, 1997.

MARTÍNEZ, C. F. et al. Dicionário de Mitologia Clássica. Lisboa: Presença, 1997.

MONTAIGNE, M. de. Montaigne. Coleção Os Pensadores, São Paulo: Nova Cultural, 1987. v.1.

PESSOA, F. Obras em Prosa. Rio de Janeiro: Nova Aguilar, 1998.

PESSOA, F. Odes de Ricardo Reis. Portugal: Europa-América, 1996.

ROSSET, C. Lógica do pior. Rio de Janeiro: Espaço e Tempo, 1989. . O Princípio de Crueldade. Rio de Janeiro: Rocco, 2002.

TRINGALI, D. Horácio poeta da festa: navegar não é preciso. São Paulo: Musa, 1995.

WEISCHEDEL, W. A Escada dos Fundos da Filosofia. A vida cotidiana e o pensamento de 34 grandes filósofos. São Paulo: Angra, 2000.

Data de Registro: 02/03/2010 Data de Aceite: 08/09/2010 
